\title{
Ice cores: High-resolution archive of rapid climate changes
}

Simon Schüpbach1', H. Fischer', S.O. Rasmussen², A. Svensson², D. Dahl-Jensen², J.P. Steffensen² and J.W.C. White ${ }^{3}$

\begin{abstract}
Owing to their outstanding temporal resolution, ice cores are well-suited to investigate rapid climate transitions during the last glacial period. They show that the climate system underwent dramatic reorganization on annual-todecadal time scales during the Dansgaard-Oeschger events.
\end{abstract}

Snow falling on the central parts of polar ice sheets is compressed to firn by the weight of the overlaying snow, eventually turning to ice through sintering and recrystallization (Herron and Langway 1980). The isotopic composition of the snow deposited on the surface (a proxy for the local condensation temperature) and impurities (such as aerosols and dust particles) are preserved in this process. In addition, air is trapped in bubbles during the transition from firn to ice, and can be extracted to study, for example, past greenhouse gas concentrations. Accordingly, the top 50-120 m of an ice sheet consists of porous snow and firn, which allows the air to circulate between the surface and the top of the firn column, while diffusive processes dominate further down the firn column (Fig. 1). Once the transformation from firn to ice is completed, the air is trapped in the ice, and the age distribution and composition of the air in the bubbles are no longer changed.

In the firn column, thermal and gravitational diffusion leads to isotopic fractionation. The isotopic composition of the gas trapped in the ice can thus be used as a temperature proxy during fast temperature changes at the surface of an ice sheet, e.g. by analyzing the ${ }^{15} \mathrm{~N} /{ }^{14} \mathrm{~N}$ ratio $\left(\delta^{15} \mathrm{~N}\right)$ of nitrogen gas (Huber et al. 2006; Kindler et al. 2014; Severinghaus et al. 1998).

Through the mixing of air in the firn column, the air entrapped in the ice is considerably younger than the surrounding ice matrix (Fig. 1). This age difference is usually denoted as $\Delta$ age, and is responsible for the uncertainties when investigating the phasing of events during fast climate transitions. $\Delta$ age depends mainly on snow accumulation and the firn temperature, such that low snow accumulation and low temperatures cause large
$\Delta$ age, and vice versa. Therefore, maximum $\triangle$ age values are observed in Antarctica e.g. in the Vostok ice core during the Last Glacial Maximum about 20'000 years ago ( $\Delta$ age of approx. 5000 years), while in Greenland $\triangle$ age values are considerably lower (up to 1400 years during the Last Glacial Maximum).

\section{Dansgaard-Oeschger events}

During the last glacial period, North Atlantic climate was not stable. The cold stadial periods were interrupted by warmer interstadial periods of durations from 100 to several thousand years. The interstadials, also called DansgaardOeschger (D-O) events, generally show a common shape in time - at the beginning, temperature increases rapidly, and subsequently decreases first slowly, then abruptly to reach stadial values again (Fig. 2a). Other climate parameters mimic this pattern. This Northern Hemisphere temperature pattern is linked to Antarctic temperature by means of the bipolar seesaw (Stocker and Johnsen 2003). This concept proposes that a reduced Atlantic Meridional Overturning Circulation (AMOC) leads to heat accumulation in the southern hemisphere (Southern Ocean) until temperature increases rapidly in the north, whereafter temperature decreases again in the south (EPICA Community Members 2006).

Due to their outstanding temporal resolution and well-constrained chronologies throughout the entire last glacial period, Greenland ice-core records are perfectly suited to investigate fast climate variations in the North Atlantic region (e.g. Huber et al. 2006; Steffensen et al. 2008), while $\mathrm{CH}_{4}$ synchronized Antarctic ice cores can be used to reconstruct mechanisms which link both hemispheres during past abrupt climate changes through the bipolar seesaw (EPICA Community Members 2006).

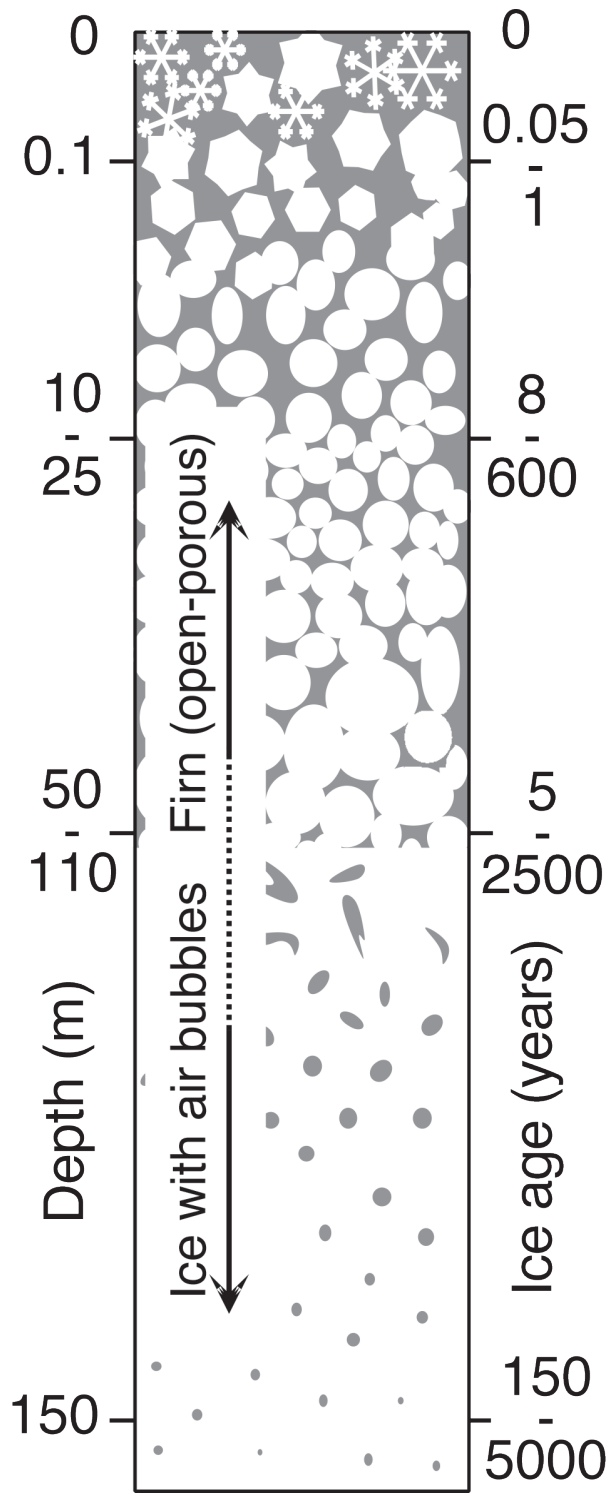

Figure 1: Schematic of the firn column with typical ranges of depth and age. Adapted from Schwander (1996). 


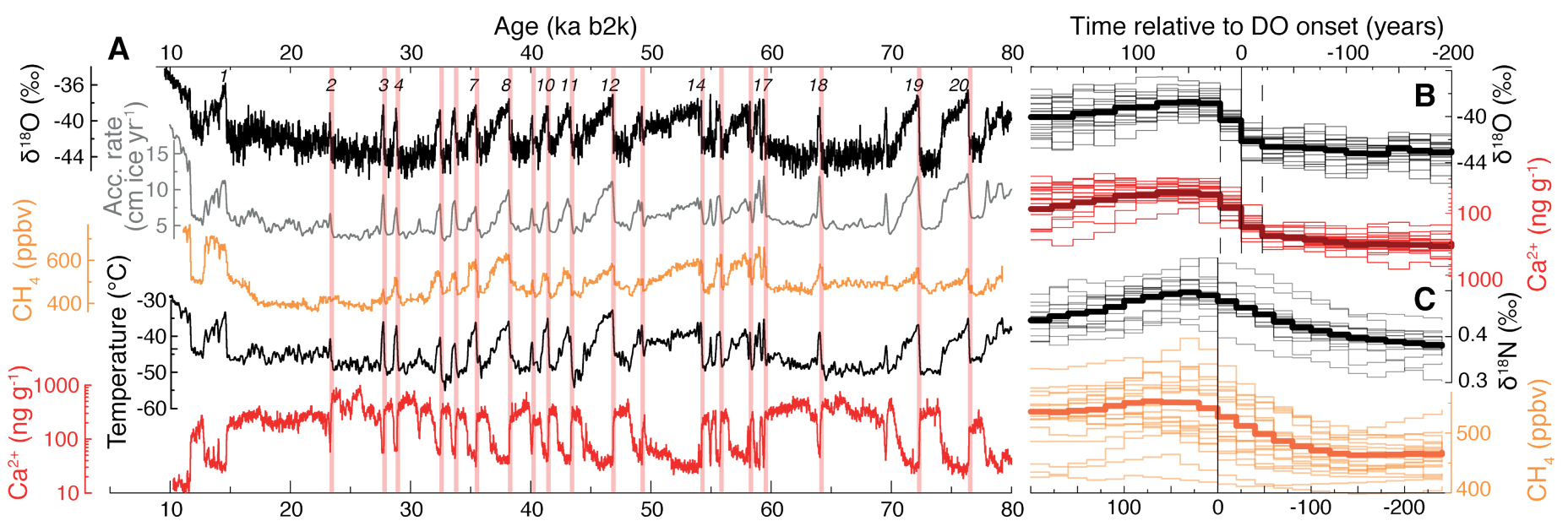

Figure 2: (A) From top to bottom: Glacial NGRIP records of $\delta^{18} \mathrm{O}$ (Rasmussen et al. 2014), accumulation rate (Kindler et al. 2014), atmospheric $\mathrm{CH}_{4}$ concentration (Baumgartner et al. 2014), $\delta^{15} \mathrm{~N}$-derived temperature (Kindler et al. 2014), and Ca ${ }^{2+}$ ice concentrations (Rasmussen et al. 2014). Italic numbers indicate D-O events. Red shades indicate the D-O onsets used in the stack on the right side. All records are plotted on the GICC05modelext age scale (Rasmussen et al. 2014; Seierstad et al. 2014). (B) Stacks of $\delta^{18} \mathrm{O}$ and $\mathrm{Ca}^{2+}$ at the rapid onsets of D-O events 2-20. A relative time of 0 years corresponds to the onset as defined by Rasmussen et al. (2014), negative time means older ages, positive time means younger ages. (C) Stacks of the rapid D-O onsets of $\mathrm{CH}_{4}$ concentration and $\delta^{15} \mathrm{~N}$ (proxy of temperature change).

\section{Duration and rates of change during D-O onsets}

In Figure $2 \mathrm{~b}$, we stack $\delta^{18} \mathrm{O}$ and $\mathrm{Ca}^{2+}$ at the onsets of D-O events 2-20. It is evident that the changes in $\delta^{18} \mathrm{O}$ and $\mathrm{Ca}^{2+}$ are equally abrupt between stadials and interstadials. The transition from stadial to interstadial conditions of $\delta^{18} \mathrm{O}$ takes place within 1-2 steps of the 20-years-resolution record. Within the data resolution, no significant lead or lag of $\mathrm{Ca}^{2+}$ relative to $\delta^{18} \mathrm{O}$ can be observed. The mean duration of the climate transition for $\mathrm{Ca}_{2}{ }^{+}$is also in the order of 40 years. Within these four decades, $\mathrm{Ca}^{2+}$ concentrations decrease by one order of magnitude, and $\delta^{18} \mathrm{O}$ increases by $3.8 \%$ on average.

The $\mathrm{Ca}^{2+}$ record is primarily reflecting changes in dust source conditions, most likely from Central Asian desert regions (Biscaye et al. 1997; Svensson et al. 2000), and transport effects. Thus, changes in $\mathrm{Ca}^{2+}$ concentration indicate reorganizations of wind fields and atmospheric circulation patterns at regional to hemispherical scale. The close relative timing of $\delta^{18} \mathrm{O}$ and $\mathrm{Ca}^{2+}$ changes indicates that the rapid changes in Greenland atmospheric dust loading and in $\delta^{18} \mathrm{O}$ may be linked to the same large-scale circulation changes.

Gas concentrations stored in ice cores change more slowly than $\delta^{18} \mathrm{O}$ and $\mathrm{Ca}^{2+}$ because they are well mixed in the atmosphere and have residence times of a decade $\left(\mathrm{CH}_{4}\right)$ or more (e.g. $\mathrm{CO}_{2}$ and $\mathrm{N}_{2} \mathrm{O}$ ). Due to gas diffusion in the firn column and the slow bubble enclosure process, fast changes of atmospheric gas concentrations are further smoothed in ice cores (Fig. 2c). Huber et al. (2006) calculated an average duration of $\delta^{15} \mathrm{~N}$ increase of $225 \pm 50$ years for D-O events $9-17 . \delta^{15} \mathrm{~N}$ is controlled by the width in the age distribution of the air enclosed in the ice and by the slow heat conductance in the firn column, which gets rid of the thermal diffusion signal. From the stack of D-O 2-20, we calculate a mean temperature jump of $10.1^{\circ} \mathrm{C}$, and a mean $\mathrm{CH}_{4}$ concentration increase of $70 \mathrm{ppb}$ (Fig. 2C). The increase of atmospheric $\mathrm{CH}_{4}$ concentration at the onset of a D-O event shows a slight lag of approximately 50 years, relative to the temperature increase recorded in $\delta^{15} \mathrm{~N}$ in line with the findings of Huber et al. (2006). A direct comparison of gas parameters and ice parameters is difficult, because $\Delta$ age uncertainty (50-100 years) is comparable to the observed differences of the start of the increase.

The durations of the fast D-O onsets discussed above can be translated into rates of change in $\mathrm{CH}_{4}$ concentrations and temperature. If we assume that $\delta^{18} \mathrm{O}$ documents the temporal change in surface temperature at the ice-core site (approx. 40 years; e.g. Steffensen et al. 2008) and take the $\delta^{15} \mathrm{~N}$-derived average temperature increase of $10.1^{\circ} \mathrm{C}$, this results in an average temperature increase of $2.5^{\circ} \mathrm{C} /$ decade. Fig. 2c shows that the increase of $\mathrm{CH}_{4}$ is slightly faster than $\delta^{15} \mathrm{~N}$. Assuming a rise time of atmospheric $\mathrm{CH}_{4}$ concentration of about 30 years and an increase of $70 \mathrm{ppb}$, this results in an average rate of change of $23 \mathrm{ppb} /$ decade, however, delayed by a few decades relative to the temperature increase. Comparing these values with modern rates of change (temperature: $0.15^{\circ} \mathrm{C} /$ decade (global) and $0.46^{\circ} \mathrm{C} /$ decade (Arctic), last 40 years; $\mathrm{CH}_{4}: 48 \mathrm{ppb} /$ decade, last 30 years) shows that Greenland temperature increased considerably faster at the onsets of D-O events than modern temperature does, but modern atmospheric $\mathrm{CH}_{4}$ concentration is increasing substantially faster than it did during D-O events. This stresses the strength of the anthropogenic $\mathrm{CH}_{4}$ perturbation in recent decades compared to the most severe natural $\mathrm{CH}_{4}$ changes, and at the same time illustrates how fast earth climate system variations can occur under glacial boundary conditions.

\section{AFFILIATIONS}

'Physics Institute and Oeschger Centre for Climate Change Research, University of Bern, Switzerland ${ }^{2}$ Niels Bohr Institute, University of Copenhagen, Denmark

${ }^{3}$ INSTAAR, University of Colorado, Boulder, USA

\section{CONTACT}

Simon Schüpbach: schuepbach@climate.unibe.ch REFERENCES

Baumgartner M et al. (2014) Clim Past 10: $903-920$ Biscaye PE et al. (1997) J Geophys Res 102: 26765-26781 EPICA Community Members (2006) Nature 444: 195-198 Herron MM, Langway CC Jr. (1980) J Glaciol 25: 373-385 Huber C et al. (2006) Earth Planet Sc Lett 243: 504-519 Kindler P et al. (2014) Clim Past 10: 887-902 Rasmussen SO et al. (2014) Quat Sci Rev 106: 14-28 Schwander J (1996) NATO ASI Series I 43: 527-540 Seierstad IK et al. (2014) Quat Sci Rev 106: 29-46 Severinghaus JP et al. (1998) Nature 391: 141-146 Steffensen JP et al. (2008) Science 321: 680-684 Stocker TF, Johnsen SJ (2003) Paleoceanography 18, doi:10.1029/2003PA000920

Svensson A et al. (2000) J Geophys Res 105: 4637-4656 